\title{
Advances in the endoscopic management of malignant biliary obstruction
}

\section{Thomas Thomaidis, , , George Kallimanisa, Gary Mayc, Pinghong Zhoud, Visvakanth Sivanathan ${ }^{b}$, Jeff Moskoc, John K. Triantafillidise, Christopher Teshima', Markus Moehler ${ }^{\text {b }}$}

Hygeia Hospital, Athens, Greece; Johannes Gutenberg University, Mainz, Germany; St' Michael's Hospital, University of Toronto, Canada; Zhongshan Hospital, Fudan University, Shanghai, China; Metropolitan General Hospital, Athens, Greece

\begin{abstract}
Biliary obstruction is common in pancreatobiliary malignancies and has a negative impact on the patient's quality of life, postoperative complications, and survival rates. Particularly in the last decade, there has been enormous progress regarding the diagnostic and therapeutic options in patients with malignant biliary obstruction. Endoscopy has given a new insight in this direction and novel techniques have been developed for the better characterization and treatment of malignant strictures. We herein summarize the available data on the different endoscopic techniques, and clarify their role in the diagnosis and treatment of malignant biliary obstructive disease. Finally, we propose an algorithm that can facilitate management decisions in these patients.
\end{abstract}

Keywords Cholangiocarcinoma, pancreatic cancer, stricture, biliary obstruction, stent, endoscopic ultrasound

Ann Gastroenterol 2020; 33 (4): 1-11

\section{Introduction}

Biliary obstruction is a common complication of malignancies of the pancreaticobiliary system that develop either as an extrinsic bile duct compression or an intrinsic growth [1]. The vast majority of patients with malignant biliary obstruction (MBO) present with an underlying pancreatic adenocarcinoma or cholangiocarcinoma (CCA). Approximately $70 \%$ of pancreatic cancer cases are located in the head of the pancreas [2], whereas $20-30 \%$ of all CCAs are found distally [3]. Other less common etiologies of obstructive jaundice include ampullary carcinoma, gallbladder

${ }^{\mathrm{a}} 2^{\text {nd }}$ Gastroenterology Clinic, Hygeia Hospital, Athens, Greece (Thomas Thomaidis, George Kallimanis); 'Johannes Gutenberg University, Mainz, Germany (Thomas Thomaidis, Visvakanth Sivanathan, Markus Moehler); 'Division of Therapeutic Endoscopy, St. Michael's Hospital, University of Toronto, Toronto, Canada (Gary May, Jeff Mosko, Christopher Teshima); 'Interventional endoscopy, Zhongshan Hospital, Fudan University, Shanghai, China (Pinghong Zhou); ${ }^{\mathrm{e}}$ Metropolitan General Hospital, Athens, Greece (John K. Triantafillidis)

Conflict of Interest: None

Correspondence to: Thomas Thomaidis, MD, PhD, $2^{\text {nd }}$ Gastroenterology Clinic, Hygeia Hospital, Erythrou Stavrou 4, Athens, Greece, e-mail: thomaidi@uni-mainz.de

Received 23 February 2020; accepted 28 April 2020; published online 25 May 2020

DOI: https://doi.org/10.20524/aog.2020.0497 carcinoma, duodenal adenocarcinoma, lymphoma, and metastatic disease [4-6].

Concerning hilar CCAs, they account for $60 \%$ of all biliary tract cancers and include tumors that originate between the cystic duct and the second order biliary radicals, and are therefore prone to causing proximal MBO. The BismuthCorlette (BC) classification (Supplementary Fig. 1) has been traditionally introduced to describe the extension of hilar CCAs along the biliary tree and to assess their resectability. Thus, lesions BC I-IIIa can be resected in more than $80 \%$ of the cases, whereas lesions staged as BC IIIb have a $55.6 \%$ chance for a curative resection [7].

Because of its subclinical presentation, $\mathrm{MBO}$ is associated with delayed diagnosis and significant morbidity. Weight loss, pruritus, malaise, abdominal discomfort or pain might just be the onset of symptoms in patients with locally advanced or metastatic disease. Furthermore, obstructive jaundice can be complicated by cholangitis, sepsis and hepatic failure $[8,9]$, thus having a negative impact on these patients' quality of life (QoL). The late symptom appearance, combined with the aggressive nature of the pancreatobiliary malignancies as well as the high operation risk, particularly in elderly patients, poses an ongoing therapeutic challenge. For example, only $20 \%$ of periampullary tumors are resectable at the time of first presentation $[10,11]$.

In this context, endoscopy provides minimally invasive and cost-effective solutions that aim at the long-term drainage of the biliary system and improvement in patients' QoL. Interestingly, endoscopy nowadays not only has a crucial role in palliation, 
but also seems to improve the diagnostic accuracy of (pre-) cancerous lesions. Cholangioscopy and intraductal ultrasound are recent novel endoscopic techniques increasingly being implemented in the diagnostic workup of pancreatobiliary malignancies.

In this article we review the endoscopic approach to $\mathrm{MBO}$, according to the level and nature of obstruction. Furthermore, we discuss future endoscopic perspectives based on recent and ongoing trials in the field of pancreatobiliary malignancies (Table 1).

\section{Diagnostic endoscopic modalities}

The early diagnosis and characterization of pancreatobiliary malignancies is the cornerstone for successful treatment. Typically, noninvasive imaging and laboratory tests comprise the first approach for the initial evaluation, followed by more invasive endoscopic techniques such as endoscopic retrograde cholangiopancreatography (ERCP) and endoscopic ultrasound (EUS).

\section{ERCP}

ERCP traditionally plays an important role in the diagnosis of the etiology of MBO. Although its diagnostic use has been limited by noninvasive radiologic modalities such as computed tomography (CT) scan and magnetic resonance imaging cholangiopancreatography (MRI-MRCP), ERCP also provides a radiographic visualization of the stricture(s) and thus provides important information about their length, location and extent. A long, irregular stricture with the presence of a "double duct sign" is considered typical for an underlying malignancy [12]. Once a suspicious stricture is detected by other imaging modalities, brushing and forceps biopsies during the ERCP can establish the diagnosis. However, the sensitivity of brush cytology ranges from $44-80 \%$ for CCA [13] and 30$60 \%$ for pancreatic cancer $[14,15]$. Navaneethan et al.. reported in a meta-analysis of 9 studies and 730 patients that brushings

Table 1 Current and future endoscopic perspectives in the management of malignant biliary strictures

\begin{tabular}{l}
\hline Diagnostic procedures \\
Endoscopic retrograde cholangiopancreatography \\
Endoscopic ultrasound (EUS) $+/$ - fine-needle aspiration \\
Peroral cholangioscopy \\
Intraductal ultrasound \\
Probe-based confocal laser endomicroscopy \\
Therapeutic procedures \\
Endoscopic retrograde cholangiopancreatography \\
EUS-guided drainage \\
EUS-choledochoduodenostomy \\
EUS-hepaticogastrostomy \\
EUS-rendezvous technique \\
EUS antegrade biliary stenting \\
Radiofrequency ablation \\
Photodynamic therapy
\end{tabular}

and intraductal biopsies show a similar diagnostic yield for malignant biliary strictures, only moderately increased when both methods are combined: sensitivity 0.59 (95\% confidence interval [CI] 0.54-0.65), specificity 1.00 (95\%CI 0.90-1.00) [14].

\section{EUS}

EUS has proven to be at least as accurate in detecting ampullary carcinoma as CT scan or MRCP. Cannon et al.. evaluated 50 patients with ampullary cancer and showed a superiority of EUS for the characterization of $\mathrm{T}$ staging compared to MRI and CT scan $(78 \%$ vs. $46 \%$ vs. $24 \%$, respectively [16]). However, this accuracy was limited to $71 \%$ when a biliary stent was present [16]. In the case of $\mathrm{MBO}$ due to pancreatic cancer or distal CCA, EUS with the use of fineneedle aspiration (FNA) can reach a sensitivity of $92 \%$ and a specificity of $96 \%$ [17] in pancreatic cancer, and up to $100 \%$ detection in distal CCA [18]. Hilar strictures appear more challenging in the establishment of diagnosis, since multiple studies demonstrated a wide range of sensitivity of EUS-FNA between $47 \%$ and $89 \%$ [12,18-20].

Lately, technical developments regarding EUS tissue acquisition and evaluation have improved its diagnostic yield. Rapid on-site cytological evaluation (ROSE) is increasingly available in many hospitals. ROSE increases the diagnostic merit of EUS-FNA to $20 \%$ and ensures patients' safety by decreasing the number of passes necessary to establish the diagnosis. Furthermore, the introduction of special designed biopsy needles (EUS-FNB) enables the acquisition of better histological samples within few passes, since they procure large volumes of tumor cells and desmoplastic stroma. Comparative studies have reported similar diagnostic accuracy for EUSFNA and FNB in pancreatic cancer [21,22]. However, recent randomized control trials have shown superiority of EUSFNB over the FNA method in terms of passes needed, sample adequacy and overall diagnostic yield [23-25].

\section{Other diagnostic endoscopic tools}

Recently, novel endoscopic modalities have been developed for the exact characterization of MBO. Direct visualization of the biliary tree is nowadays feasible with the use of a single-operator cholangioscope with integrated digital sensors (SpyGlass ${ }^{\mathrm{TM}}$ ), while specially designed biopsy forceps (SpyBite) allow for directed specimen acquisition. Peroral cholangioscopy (POCS) has shown promising results, with a diagnostic accuracy of more than $80 \%$ in both visual inspection and cholangioscopyguided biopsies [26]. The sensitivity and specificity of the diagnosis of malignancy based on visual impression during POCS is reported to be above $90 \%$, whereas cholangioscopytargeted biopsies appear to have a slightly lower sensitivity of around $60-85 \%$ [27-29]. Intraductal malignant growths can be easily distinguished because of their irregular vascular pattern, nodularity, papillary morphology and bleeding tendency (Fig. 1) [30-32]. However, POCS has certain limitations, 


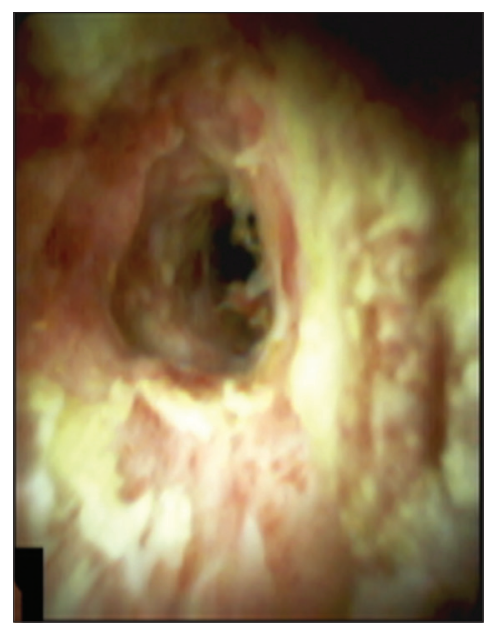

Figure 1 Cholangioscopic image hyperemic of a malignant stricture in the proximal bile duct. The lesion is hyperemic, has irregular borders and shows papillary protrusions

particularly in the case of extrinsic strictures or distal CCAs, due to the unstable scope position [33].

Intraductal ultrasound involves a radial probe being introduced into the bile duct over a guidewire. Although its accuracy for $\mathrm{MBO}$ reaches $95 \%$ [34], its clinical value is somewhat limited by the reduced maneuverability through the bile tract and the lack of tissue acquisition. Probe-based confocal laser endomicroscopy (pCLE) is a promising endoscopic technique that provides in vivo imaging during ERCP. Fluorescein, a contrast agent, is typically injected intravenously and yields good contrast of vessels and tissue architecture. Meining et al, in a prospective trial of 102 patients, reported a sensitivity of $98 \%$ and a specificity of $67 \%$ [35] in detecting MBO. However, its poor interobserver agreement [36] and high costs have limited its use.

\section{Therapeutic endoscopic modalities}

\section{Preoperative treatment}

\section{Distal MBO}

Preoperative biliary drainage (PBD) has been an issue of debate over the last decade. Although hyperbilirubinemia has been associated with increased morbidity and mortality, multiple meta-analyses have demonstrated worse postoperative outcomes in patients with distal obstruction treated with PBD [37-39]. In particular, in a large randomized control trial (RCT) van der Gaag et al showed higher complication rates in patients who had PBD compared to those without preoperative treatment (74\% vs. $39 \%$ [40]).

However, certain conditions, such as cholangitis, severe symptomatic jaundice, delayed surgery and neoadjuvant therapy have been embraced by international guidelines [33,41] as main indications for PBD. Preoperative bilirubin levels above $300 \mu \mathrm{mol} / \mathrm{L}$ serve as a cutoff for severe postoperative complications and poorer long-term survival, as shown in a recently published retrospective study of 1200 patients [42].

Regarding the preferred route, the endoscopic approach should be favored over the percutaneous approach, since the latter has been associated with tract seeding, lower survival rates, and a higher risk of recurrence [43-45].

\section{Type of stent}

The recommended type of stent for PBD has been the subject of investigation in many studies, including some without an oncological primary endpoint [46-48]. The majority of them support the findings of a Dutch RCT conducted in patients with pancreatic cancer: the use of fully covered self-expandable metal stents (fcSEMS) resulted in fewer perioperative adverse events compared with the group treated with plastic stents (PS) (24\% vs. $46 \%$ ) [49]. Compared to uncovered SEMS (uSEMS), fcSEMS seem to have a longer patency and duration as well as fewer days of delay for chemotherapy onset [46]. However, in a recent RCT of 119 patients with distal MBO uSEMS showed equal results in biliary drainage (BD) compared to fcSEMS (72.2\% vs. 72.9\%) [50].

\section{Proximal MBO}

According to the current guidelines of the European Society for Gastrointestinal Endoscopy [41], endoscopists and radiologists should refrain from PBD in hilar malignancies unless cholangitis is present or the predicted future liver remnant volume following surgery is less than 30\% [51]. There have been controversial data regarding the preferred route of stenting [52,53]. Nonetheless, we should take into consideration that the technical success in patients with proximal MBO is lower when the endoscopic approach is preferred [54]. The final choice should take into account the available expertise and the exact localization of the stricture. PS are favored over fcSEMS, but further studies are necessary [41].

\section{Palliative treatment}

\section{Distal MBO}

Surgical bypass was the initial approach to treating cholestasis in patients with distal $\mathrm{MBO}$, given the low rates of recurrent jaundice (2-5\%). Nevertheless, surgery was soon replaced by radiographic and endoscopic techniques because of its high risk of postoperative morbidity and mortality $[55,56]$. Compared to percutaneous transhepatic BD (PTBD), ERCP is the preferred initial approach. It has a lower rate of adverse events ( $8.6 \%$ vs. $12.3 \%$ ) and shorter hospitalization. Furthermore, it is associated with fewer repeated procedures and lower costs, and it is physically better tolerated by patients [57]. In case of failed access or difficult biliary cannulation, other techniques such as PTBD or EUS-guided BD (EUS-BD) are appropriate.

SEMS are favored over PS, as shown in multiple metaanalyses [58-62]. They demonstrate longer patency and 
patient survival, fewer adverse events and lower reintervention rates. Regarding cost efficacy, there seem to be no significant differences between PS and SEMS. Interestingly, in a recent RCT conducted in The Netherlands [63], costs were demonstrated to be similar in both groups, even in patients with a life expectancy of $<3$ months or metastatic disease.

The big question, however, is whether fcSEMS or uSEMS should be the gold standard for drainage in patients with distal MBO. The data from various meta-analyses have shown conflicting results [64-66]. All of them agree that, compared with uSEMS, fcSEMS have longer patency but are more prone to migration. However, none of these stents have demonstrated a significant survival benefit. Because of the patency benefit, a recently published international consensus expresses a weak preference for fcSEMS for pancreatic MBO [33].

Another challenging issue in patients affected by distal tumors is concomitant biliary and duodenal malignant obstruction. These are classified into 3 different types [67]: type I, in which duodenal strictures are present in the first part of the duodenum; type II, in which the duodenal stenosis involves the papilla; and type III, in which duodenal stenosis occurs distally from the papilla. Unlike type I and III lesions, where the duodenal and biliary stents do not interact with each other, in type II lesions accessing the ampulla, especially the native ampulla, through the mesh of the duodenal uSEMS is associated with a percentage of failure up to $60 \%$ [68]. Therefore, endoscopic transpapillary $\mathrm{BD}$ before duodenal stent insertion is recommended if the duodenoscope can pass through the duodenal stricture [69]. Otherwise, combination with PTBD, removal of some of the wires of the duodenal mesh with rat-tooth forceps, or destroying the mesh wire using argon plasma coagulation might be useful to gain access to the biliary orifice. Recently, a novel duodenal SEMS with expandable lattices in the mid portion has been reported to facilitate biliary stent deployment in $91.7 \%$ of the cases [70]. Nevertheless, the choice of the endoscopic approach is based on expertise and exact location of the tumor.

\section{Proximal MBO}

In patients with hilar $\mathrm{MBO}$, stenting aims to ensure drainage of $\geq 50 \%$ of the total liver volume, associated with prolonged survival and improved QoL [71]. Although PTBD has been shown to have greater technical success than stenting via ERCP [54], its major drawbacks-inconvenience to the patient, leaking, seeding and infection risk, reduced QoLhave given endoscopy the role of primary intervention in the palliative setting.

Similarly to studies in distal MBO, several RCTs in patients with hilar malignancy demonstrated a superiority of SEMS over PS in patients with a life expectancy of over 4 months [72-74]. uSEMS are to be preferred, because occlusion of small bile ducts by an fCSEMS might increase the risk of cholangitis.

The choice between unilateral or bilateral stents is based on the morphology of the hilar malignancy and the segments that need to be drained. Although Bismuth I tumors can be approached similarly to distal MBO, Bismuth II-IV tumors still remain a field of controversy. CT scan can assess the percentage of the total liver volume affected by the strictures and therefore justify the choice of bilateral drainage, especially in Bismuth type III or IV lesions. Unilateral drainage appears to be technically less challenging, and it demonstrates similar outcomes with bilateral stenting according to 2 RCTs $[74,75]$. However, in 2 recent Asian RCTs, bilateral stenting for Bismuth type III-V strictures showed a higher clinical success rate $(84.9$ vs. $95.3 \%, \mathrm{P}=0.047)$ and a lower reintervention rate (60.3 vs. $42.6 \%, \mathrm{P}=0.049$ ) compared to unilateral [76,77].

In any case, endoscopic drainage of complex malignant hilar strictures is technically demanding and might require multiple SEMS. In a recent large retrospective Italian study, SEMS malfunction was usually attributed to sludge formation, in $65.9 \%$ of the cases, or to overgrowth and ingrowth (34.1\% [78]). Such cases require recannulation of the duct through the occluded stent. Sludge and clots can be mechanically removed with the ERCP balloon, whereas ingrowth and overgrowth can be treated by placing another uSEMS inside the previous one.

There are 2 methods for bilateral endoscopic drainage. In the stent-in-stent (SIS) technique a second USEMS is placed through the mesh of the first one into the contralateral hepatic duct, whereas in the stent-by-stent (SBS) technique both of the stents are inserted and placed, simultaneously or one after the other, side by side into the left and the right hepatic duct. The branch more difficult for cannulation should be selected as the first stent placement target, to ensure easy insertion of the second stent. Otherwise, balloon dilation of the contralateral hepatic duct immediately before the first stenting might facilitate second SEMS insertion.

Both techniques are considered equivalent in terms of successful drainage, complications and occlusion rates [79-81]. However, unpublished data from Korea indicate that the SIS method might have a tendency towards a higher rate of stent patency compared to SBS. Hence, each case has to be assessed individually and evaluated regarding expertise, pros and cons.

\section{Stent evolution}

Stent migration and re-occlusion due to tumor ingrowth are major disadvantages of covered and uncovered SEMS, respectively; therefore, special strategies have been developed. Paclitaxel-eluting stents showed no apparent benefits in a recent RCT involving 72 patients [82]. In 2 RCTs of 23 and 55 patients $[83,84]$, SEMS combined with radioactive seeds (I125) showed promising results regarding patency and survival (mean survival of 8 months vs. 3 months [83]) compared to a similar, nonradioactive, stent.

To overcome the problem of migration, SEMS with anchoring flaps, flared ends or differential radial expansive forces have been studied. Park et al showed that stents with antimigration flaps migrate less often than flared-end stents [85]. Furthermore, a double pigtail PS could serve as an anchor and prevent migration when inserted through a fcSEMS. Duodenal biliary reflux has also been described as a result of the impaired sphincter function due to the inserted SEMS [86]. Novel stents with an antireflux valve have been developed and have shown promising results in 2 RCTs $[87,88]$. However, latest data from 
Japan point out the need for further investigation and technical improvement [89].

\section{Novel endoscopic techniques}

\section{Radiofrequency ablation (RFA) and photodynamic therapy (PDT)}

Recently, local therapies such as RFA or PDT have been developed for the treatment of MBO. Intraductal RFA can be performed either endoscopically or percutaneously, through the insertion of a bipolar catheter over a guidewire that delivers alternating currents and thus causes localized thermal injury and necrosis. RFA has been described before stent placement, or even after, in order to ablate the tumor ingrowth in occluded stents. It has shown significant clinical outcomes in distal and proximal MBO, as well as a benefit in terms of patients' survival. In a meta-analysis from Sofi et al, the application of RFA led to longer stent patency (50 vs. 37 days, $\mathrm{P}<0.002$ ) and patients' survival (285 vs. 248 days, $\mathrm{P}<0.001$ ) [90]. Similarly, a recent trial from Japan demonstrated a median time to obstruction recurrence of 230 days in hilar tumors when RFA was combined with bilateral stenting [91]. Stent patency was significantly longer in strictures $\geq 15 \mathrm{~mm}$ [91]. However, the majority of the studies in the literature had a retrospective design and the only 2 RCTs were performed with PS after RFA [92,93].

PDT is a 2-step process that requires the injection of an intravenous porphyrin photosensitizing agent followed by selective intraductal laser photo-radiation during endoscopy. PDT has been reported to increase stent patency, QoL, and survival [94-96]. Systemic photosensitivity occurs in $10 \%$ of cases as the most important adverse event. Nonetheless, its role in the palliation of $\mathrm{MBO}$ is limited by significant costs and need for operator expertise [95]. Both of these adjunctive techniques might also be promising, but are still considered investigational therapies for MBO [33].

\section{EUS-BD}

Since 1996, when Wiersema reported the first EUS-guided cholangiopancreatography [97], and 2001, when Giovannini performed the first EUS-assisted choledochoduodenostomy (CDS) [98], there has been an increased interest in the utility of EUS-BD in patients with benign and malignant biliary obstructions. EUS-BD is further categorized, according to the route of approach and the site of $\mathrm{BD}$, as CDS, hepaticogastrostomy (HGS), rendezvous technique (RV), and antegrade biliary stenting. Briefly, a sectorial echoendoscope identifies the dilated hepatic ducts or the bile duct. The duct of interest is then punctured with a 19-G needle and a guidewire is placed to guide the stent through the gastric or duodenal wall (Fig. 2). Alternatively, the guidewire can be exteriorized through the papilla into the second part of the duodenum and a SEMS can be forwarded in an antegrade fashion transpapillary. In the RV technique, once the guidewire is guided through

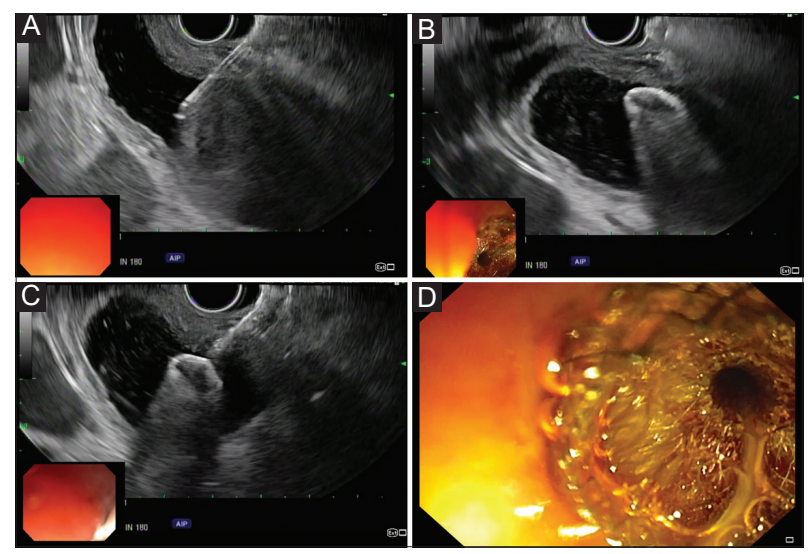

Figure 2 Steps of EUS-CDS. The dilated bile duct is punctured under EUS-guidance with a 19-g FNA needle (A). The distal end of the LAMS is deployed in means of an electrocautery enhanced delivery system in the dilated lumen (B). The distal part of the deployed LAMS is pulled closed to the wall of the bile duct (C). Deployment of the proximal end of the LAMS in the duodenal lumen under endoscopic guidance (D) EUS, endoscopic ultrasound; FNA, fine-needle aspiration; CDS, choledochoduodenostomy; LAMS, lumen-apposing metal stent

the papilla the echoendoscope is withdrawn and the stent is advanced in the obstructed duct by means of a duodenoscope.

Compared to PTBD, EUS-BD is similarly effective but is associated with a lower rate of adverse events and fewer reinterventions $[99,100]$. EUS-BD has high technical and clinical success rates [101], is less expensive than PTBD and improves patients' QoL, since external drainage might cause skin irritations, infections or leakage. Therefore, current international consensus guidelines recommend EUS-BD after failed ERCP if the expertise is available $[102,103]$.

The efficacy of EUS-BD as a first-line treatment for malignant decompression is the subject of recent and ongoing studies. Emerging data from 3 recent prospective trials and 1 meta-analysis [104-107] described similar technical success rates and clinical outcomes between EUS- and ERCP-assisted primary BD. There was no significant difference in terms of procedure time or the risk of stent occlusion; however, EUS-BD was associated with a lower risk of pancreatitis (risk ratio 0.22 , 95\%CI 0.05-1.02) [107]. These results remain to be confirmed in the ELEMENT trial, an ongoing multicenter prospective RCT that involves 9 Canadian centers [108].

Regarding the recommended route of approach, EUS-RV seems to be the safest of all procedures-should conditions permit-because it respects the patients' anatomy. Experts agree that the access and drainage routes in EUS-assisted biliary interventions should be chosen depending on the indication, the level of the biliary obstruction, the anatomical condition of the upper gastrointestinal tract and the operator's experience [103]. However, EUS-RV involves certain pitfalls, since it is associated with a risk of pancreatitis due to the manipulation of the papilla, it requires a longer intervention time and it is technically more challenging.

The choice between CDS and HGS has mostly to do with the level of obstruction and the patient's anatomy. CDS is well 
tolerated with shorter intervention time, whereas EUS-HGS has a higher level of difficulty and a longer learning curve: the targeted duct lies most commonly in segment 3 of the liver and the puncture is performed through the thick gastric wall.

Over the last decade, SEMS have been introduced in EUS-BD. Recently, the use of lumen apposing metal stents for CDS has been increasing, since they provide lower migration rates and a smaller risk of bile leakage [109]. Furthermore, specially designed SEMS and PS have been proposed for use in HGS [110,111]. These stents are mostly $8-10 \mathrm{~cm}$ long, because a longer luminal length seems to be associated with long-term stent patency [112].

\section{Concluding remarks}

Endoscopy has brought a new era in the field of management of MBO. It provides patients with minimally invasive diagnostic and therapeutic tools that improve the QoL in the palliative setting, and ensure lower postoperative complication rates and longer survival. Cholangioscopy and pCLE are promising diagnostic modalities, which in combination with tissue-based genetic tests (fluorescence in situ hybridization and flow cytometry) seem to have a role to play in future diagnostics. Furthermore, the introduction of EUS-assisted drainage has shown a new way of successful and safe management of MBO. We believe that future perspectives of EUS-BD will also include the primary decompression of the obstructive ducts (Fig. 3, 4). However, further studies are necessary to optimize the indications and technical flaws of the material used. The bottom line is that $\mathrm{MBO}$ is a complex entity and the decision concerning its diagnostic and/or therapeutic management should be based on personalized criteria, the location of the stricture, and the operator's expertise.

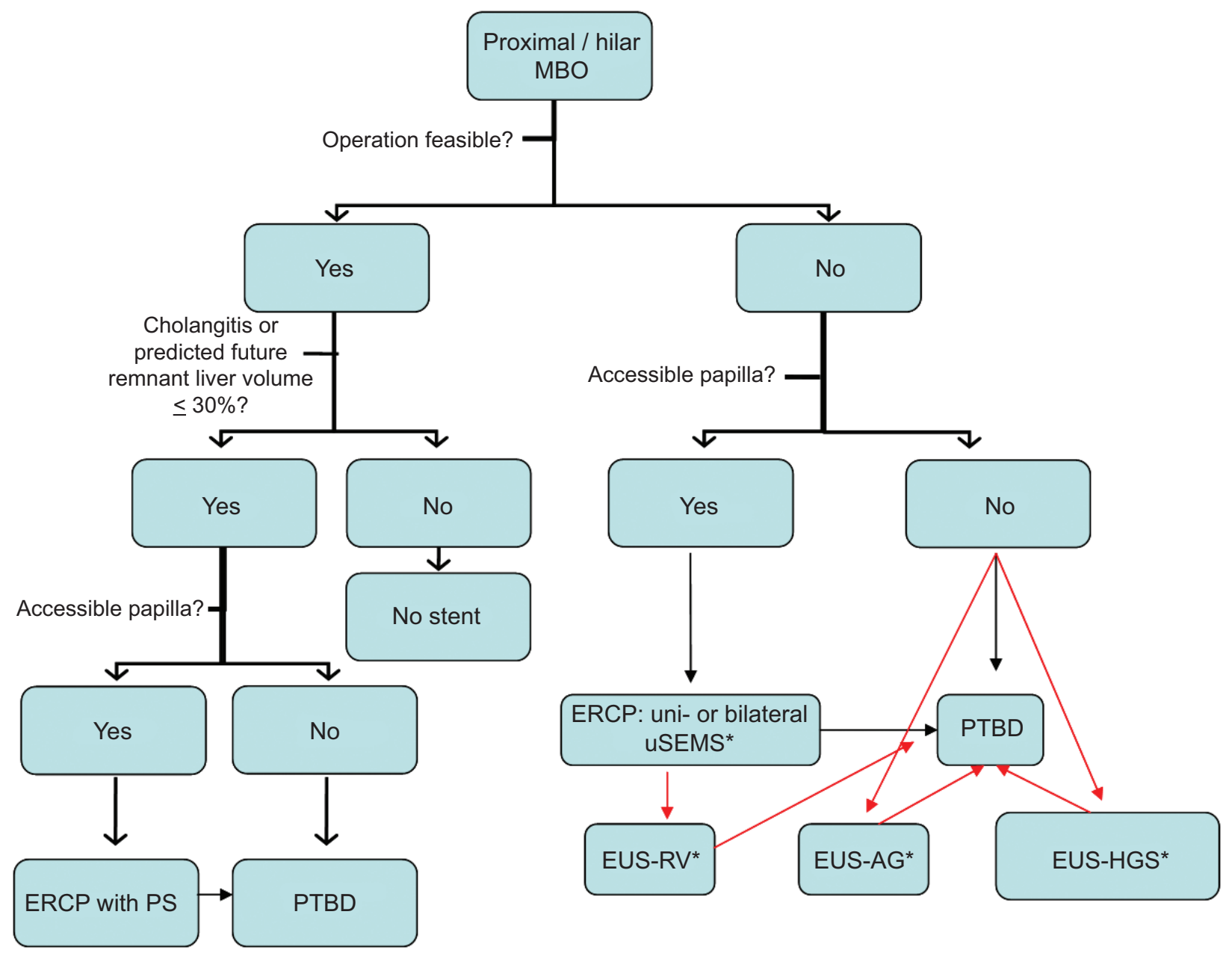

Figure 3 Simplified algorithm of management for patients with proximal/hilar MBO. The red arrows indicate future tendencies ${ }^{*}$ Taking into account the level of obstruction and expertise $M B O$, malignant biliary obstruction; ERCP, endoscopic retrograde cholangiopancreatography; PTBD, percutaneous transhepatic biliary drainage; uSEMS, uncovered self-expandable metal stents; PS, plastic stents; EUS-RV, endoscopic ultrasound rendezvous technique; EUS-AG, endoscopic ultrasound antegrade biliary stenting; EUS-HGS, endoscopic ultrasound hepaticogastrostomy 


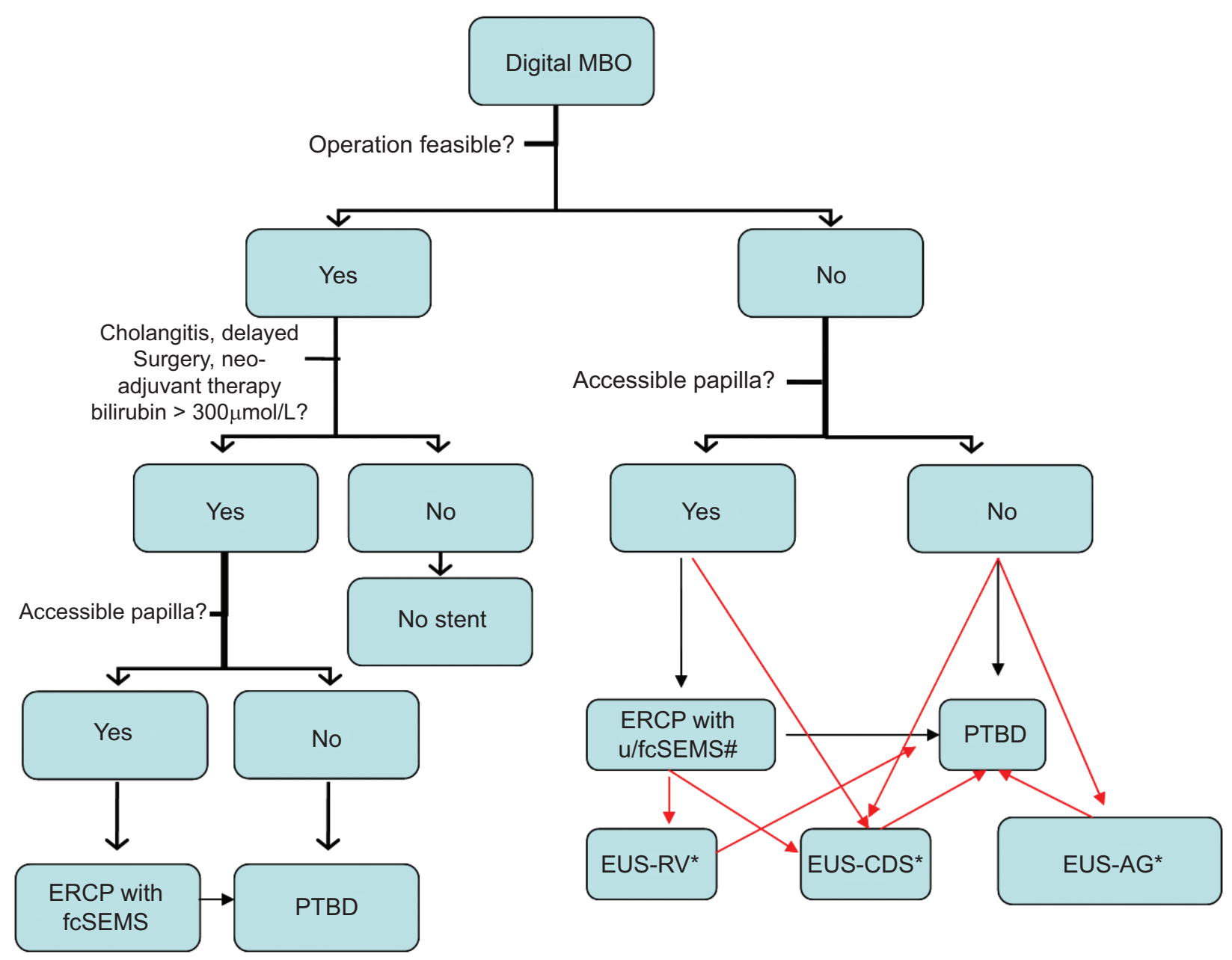

Figure 4 Simplified algorithm of management for patients with distal MBO. The red arrows indicate future tendencies ${ }^{\star}$ Taking into account the level of obstruction and expertise \#weak preference for fcSEMS

$M B O$, malignant biliary obstruction; ERCP, endoscopic retrograde cholangiopancreatography; PTBD, percutaneous transhepatic biliary drainage; USEMS, uncovered self-expandable metal stents; fCSEMS, fully covered self-expandable metal stent; EUS-RV, endoscopic ultrasound rendezvous technique; EUS-AG, endoscopic ultrasound antegrade biliary stenting; EUS-CDS, endoscopic ultrasound choledochoduodenostomy

\section{References}

1. Pu LZ, Singh R, Loong CK, de Moura EG. Malignant biliary obstruction: evidence for best practice. Gastroenterol Res Pract 2016;2016:3296801.

2. Hidalgo M. Pancreatic cancer. N Engl J Med 2010;362:1605-1617.

3. Rizvi S, Khan SA, Hallemeier CL, Kelley RK, Gores GJ. Cholangiocarcinoma - evolving concepts and therapeutic strategies. Nat Rev Clin Oncol 2018;15:95-111.

4. Lokich JJ, Kane RA, Harrison DA, McDermott WV. Biliary tract obstruction secondary to cancer: management guidelines and selected literature review. J Clin Oncol 1987;5:969-981.

5. Parasher G, Lee J. The role of ERCP in pancreaticobiliary malignancies. In: Adv Dig Endosc ERCP 2005: 120-141.

6. van Berkel A, Fockens P, Bruno M. Palliation of malignant pancreatobiliary obstruction. Saunders: USA; 2005 pp 821-837.

7. Passeri MJ, Baimas-George MR, Sulzer JK, et al. Prognostic impact of the Bismuth-Corlette classification: Higher rates of local unresectability in stage IIIb hilar cholangiocarcinoma.
Hepatobiliary Pancreat Dis Int 2020;19:157-162.

8. Strasberg SM, Gao F, Sanford D, et al. Jaundice: an important, poorly recognized risk factor for diminished survival in patients with adenocarcinoma of the head of the pancreas. HPB (Oxford) 2014;16:150-156.

9. Boulay BR, Birg A. Malignant biliary obstruction: From palliation to treatment. World J Gastrointest Oncol 2016;8:498-508.

10. Ryan DP, Hong TS, Bardeesy N. Pancreatic adenocarcinoma. N Engl J Med 2014;371:1039-1049.

11. Albores-Saavedra J, Schwartz AM, Batich K, Henson DE. Cancers of the ampulla of vater: demographics, morphology, and survival based on 5,625 cases from the SEER program. J Surg Oncol 2009;100:598-605.

12. Singh A, Gelrud A, Agarwal B. Biliary strictures: diagnostic considerations and approach. Gastroenterol Rep (Oxf) 2015;3:22-31.

13. De Bellis M, Sherman S, Fogel EL, et al. Tissue sampling at ERCP in suspected malignant biliary strictures (Part 1). Gastrointest Endosc 2002;56:552-561.

14. Navaneethan U, Njei B, Lourdusamy V, Konjeti R, Vargo JJ, 
Parsi MA. Comparative effectiveness of biliary brush cytology and intraductal biopsy for detection of malignant biliary strictures: a systematic review and meta-analysis. Gastrointest Endosc 2015;81:168-176.

15. Burnett AS, Calvert TJ, Chokshi RJ. Sensitivity of endoscopic retrograde cholangiopancreatography standard cytology: 10-y review of the literature. J Surg Res 2013;184:304-311.

16. Cannon ME, Carpenter SL, Elta GH, et al. EUS compared with CT, magnetic resonance imaging, and angiography and the influence of biliary stenting on staging accuracy of ampullary neoplasms. Gastrointest Endosc 1999;50:27-33.

17. Chen J, Yang R, Lu Y, Xia Y, Zhou H. Diagnostic accuracy of endoscopic ultrasound-guided fine-needle aspiration for solid pancreatic lesion: a systematic review. J Cancer Res Clin Oncol 2012;138:1433-1441.

18. Mohamadnejad M, DeWitt JM, Sherman S, et al. Role of EUS for preoperative evaluation of cholangiocarcinoma: a large singlecenter experience. Gastrointest Endosc 2011;73:71-78.

19. Rösch T, Hofrichter K, Frimberger E, et al. ERCP or EUS for tissue diagnosis of biliary strictures? A prospective comparative study. Gastrointest Endosc 2004;60:390-396.

20. DeWitt J, Misra VL, Leblanc JK, McHenry L, Sherman S. EUSguided FNA of proximal biliary strictures after negative ERCP brush cytology results. Gastrointest Endosc 2006;64:325-333.

21. Lee YN, Moon JH, Kim HK, et al. Core biopsy needle versus standard aspiration needle for endoscopic ultrasound-guided sampling of solid pancreatic masses: a randomized parallel-group study. Endoscopy 2014;46:1056-1062.

22. Wang J, Zhao S, Chen Y, Jia R, Zhang X. Endoscopic ultrasound guided fine needle aspiration versus endoscopic ultrasound guided fine needle biopsy in sampling pancreatic masses: A meta-analysis. Medicine (Baltimore) 2017;96:e7452.

23. Cheng B, Zhang Y, Chen Q, et al. Analysis of fine-needle biopsy vs fine-needle aspiration in diagnosis of pancreatic and abdominal masses: a prospective, multicenter, randomized controlled trial. Clin Gastroenterol Hepatol 2018;16:1314-1321.

24. Kamata K, Kitano M, Yasukawa S, et al. Histologic diagnosis of pancreatic masses using 25-gauge endoscopic ultrasound needles with and without a core trap: a multicenter randomized trial. Endoscopy 2016;48:632-638.

25. Aadam AA, Wani S, Amick A, et al. A randomized controlled cross-over trial and cost analysis comparing endoscopic ultrasound fine needle aspiration and fine needle biopsy. Endosc Int Open 2016;4:E497-E505.

26. Korrapati P, Ciolino J, Wani S, et al. The efficacy of peroral cholangioscopy for difficult bile duct stones and indeterminate strictures: a systematic review and meta-analysis. Endosc Int Open 2016;4:E263-E275.

27. Navaneethan U, Hasan MK, Kommaraju K, et al. Digital, single-operator cholangiopancreatoscopy in the diagnosis and management of pancreatobiliary disorders: a multicenter clinical experience (with video). Gastrointest Endosc 2016;84:649-655.

28. Ogura T, Imanishi M, Kurisu Y, et al. Prospective evaluation of digital single-operator cholangioscope for diagnostic and therapeutic procedures (with videos). Dig Endosc 2017;29:782-789.

29. Pereira P, Santos S, Morais R, et al. Role of peroral cholangioscopy for diagnosis and staging of biliary tumors. Dig Dis 2020 [Epub ahead of print].

30. Robles-Medranda C, Valero M, Soria-Alcivar M, et al. Reliability and accuracy of a novel classification system using peroral cholangioscopy for the diagnosis of bile duct lesions. Endoscopy 2018;50:1059-1070.

31. Kim HJ, Kim MH, Lee SK, Yoo KS, Seo DW, Min YI. Tumor vessel: a valuable cholangioscopic clue of malignant biliary stricture. Gastrointest Endosc 2000;52:635-638.
32. Itoi $\mathrm{T}$, Osanai $\mathrm{M}$, Igarashi $\mathrm{Y}$, et al. Diagnostic peroral video cholangioscopy is an accurate diagnostic tool for patients with bile duct lesions. Clin Gastroenterol Hepatol 2010;8:934-938.

33. Nakai $Y$, Isayama $H$, Wang $H P$, et al. International consensus statements for endoscopic management of distal biliary stricture. J Gastroenterol Hepatol 2019 Dec 4 [Epub ahead of print].

34. Tabibian JH, Visrodia KH, Levy MJ, Gostout CJ. Advanced endoscopic imaging of indeterminate biliary strictures. World $J$ Gastrointest Endosc 2015;7:1268-1278.

35. Meining A, Chen YK, Pleskow D, et al. Direct visualization of indeterminate pancreaticobiliary strictures with probe-based confocal laser endomicroscopy: a multicenter experience. Gastrointest Endosc 2011;74:961-968.

36. Talreja JP, Sethi A, Jamidar PA, et al. Interpretation of probe-based confocal laser endomicroscopy of indeterminate biliary strictures: is there any interobserver agreement? Dig Dis Sci 2012;57:3299-3302.

37. Sewnath ME, Karsten TM, Prins MH, Rauws EJ, Obertop H, Gouma DJ. A meta-analysis on the efficacy of preoperative biliary drainage for tumors causing obstructive jaundice. Ann Surg 2002;236:17-27.

38. Lee PJ, Podugu A, Wu D, Lee AC, Stevens T, Windsor JA. Preoperative biliary drainage in resectable pancreatic cancer: a systematic review and network meta-analysis. HPB (Oxford) 2018;20:477-486.

39. Scheufele F, Schorn S, Demir IE, et al. Preoperative biliary stenting versus operation first in jaundiced patients due to malignant lesions in the pancreatic head: A meta-analysis of current literature. Surgery 2017;161:939-950.

40. van der Gaag NA, Rauws EA, van Eijck CH, et al. Preoperative biliary drainage for cancer of the head of the pancreas. $N$ Engl $J$ Med 2010;362:129-137.

41. Dumonceau JM, Tringali A, Papanikolaou IS, et al. Endoscopic biliary stenting: indications, choice of stents, and results: European Society of Gastrointestinal Endoscopy (ESGE) Clinical Guideline - Updated October 2017. Endoscopy 2018;50:910-930.

42. Sauvanet A, Boher JM, Paye F, et al; French Association of Surgery. Severe jaundice increases early severe morbidity and decreases long-term survival after pancreaticoduodenectomy for pancreatic adenocarcinoma J Am Coll Surg 2015;221:380-389.

43. Miura F, Sano K, Wada K, et al. Prognostic impact of type of preoperative biliary drainage in patients with distal cholangiocarcinoma. Am J Surg 2017;214:256-261.

44. Strom TJ, Klapman JB, Springett GM, et al. Comparative long-term outcomes of upfront resected pancreatic cancer after preoperative biliary drainage. Surg Endosc 2015;29:3273-3281.

45. Uemura K, Murakami Y, Satoi S, et al. Impact of preoperative biliary drainage on long-term survival in resected pancreatic ductal adenocarcinoma: a multicenter observational study. Ann Surg Oncol 2015;22 Suppl 3:S1238-S1246.

46. Gardner TB, Spangler CC, Byanova KL, et al. Cost-effectiveness and clinical efficacy of biliary stents in patients undergoing neoadjuvant therapy for pancreatic adenocarcinoma in a randomized controlled trial. Gastrointest Endosc 2016;84:460-466.

47. Adams MA, Anderson MA, Myles JD, Khalatbari S, Scheiman JM. Self-expanding metal stents (SEMS) provide superior outcomes compared to plastic stents for pancreatic cancer patients undergoing neoadjuvant therapy. J Gastrointest Oncol 2012;3:309-313.

48. Tsuboi T, Sasaki T, Serikawa M, et al. Preoperative biliary drainage in cases of borderline resectable pancreatic cancer treated with neoadjuvant chemotherapy and surgery. Gastroenterol Res Pract 2016;2016:7968201.

49. Tol JA, van Hooft JE, Timmer R, et al. Metal or plastic stents for preoperative biliary drainage in resectable pancreatic cancer. Gut 2016;65:1981-1987.

50. Seo DW, Sherman S, Dua KS, et al; Biliary SEMS During 
Neoadjuvant Therapy Study Group. Covered and uncovered biliary metal stents provide similar relief of biliary obstruction during neoadjuvant therapy in pancreatic cancer: a randomized trial. Gastrointest Endosc 2019;90:602-612.

51. Wiggers JK, Groot Koerkamp B, Cieslak KP, et al. Postoperative mortality after liver resection for perihilar cholangiocarcinoma: development of a risk score and importance of biliary drainage of the future liver remnant. J Am Coll Surg 2016;223:321-331.

52. Hameed A, Pang T, Chiou J, et al. Percutaneous vs. endoscopic preoperative biliary drainage in hilar cholangiocarcinoma - a systematic review and meta-analysis. HPB (Oxford) 2016;18:400-410.

53. Al Mahjoub A, Menahem B, Fohlen A, et al. Preoperative biliary drainage in patients with resectable perihilar cholangiocarcinoma: is percutaneous transhepatic biliary drainage safer and more effective than endoscopic biliary drainage? A meta-analysis. J Vasc Interv Radiol 2017;28:576-582.

54. Moole H, Dharmapuri S, Duvvuri A, et al. Endoscopic versus percutaneous biliary drainage in palliation of advanced malignant hilar obstruction: a meta-analysis and systematic review. Can J Gastroenterol Hepatol 2016;2016:4726078.

55. Ho CS, Warkentin AE. Evidence-based decompression in malignant biliary obstruction. Korean J Radiol 2012;13(Suppl 1):S56-S61.

56. Distler M, Kersting S, Rückert F, et al. Palliative treatment of obstructive jaundice in patients with carcinoma of the pancreatic head or distal biliary tree. Endoscopic stent placement vs. hepaticojejunostomy. JOP 2010;11:568-574.

57. Inamdar S, Slattery E, Bhalla R, Sejpal DV, Trindade AJ. Comparison of adverse events for endoscopic vs percutaneous biliary drainage in the treatment of malignant biliary tract obstruction in an inpatient national cohort. JAMA Oncol 2016;2:112-117.

58. Moole H, Jaeger A, Cashman M, et al. Are self-expandable metal stents superior to plastic stents in palliating malignant distal biliary strictures? A meta-analysis and systematic review. Med J Armed Forces India 2017;73:42-48.

59. Sawas T, Al Halabi S, Parsi MA, Vargo JJ. Self-expandable metal stents versus plastic stents for malignant biliary obstruction: a meta-analysis. Gastrointest Endosc 2015;82:256-267.

60. Zorrón Pu L, de Moura EG, Bernardo WM, et al. Endoscopic stenting for inoperable malignant biliary obstruction: A systematic review and meta-analysis. World J Gastroenterol 2015;21:13374-13385.

61. Almadi MA, Barkun A, Martel M. Plastic vs. self-expandable metal stents for palliation in malignant biliary obstruction: a series of meta-analyses. Am J Gastroenterol 2017;112:260-273.

62. Hong WD, Chen XW, Wu WZ, Zhu QH, Chen XR. Metal versus plastic stents for malignant biliary obstruction: an update metaanalysis. Clin Res Hepatol Gastroenterol 2013;37:496-500.

63. Walter D, van Boeckel PG, Groenen MJ, et al. Cost efficacy of metal stents for palliation of extrahepatic bile duct obstruction in a randomized controlled trial. Gastroenterology 2015;149:130-138.

64. Yang Z, Wu Q, Wang F, Ye X, Qi X, Fan D. A systematic review and meta-analysis of randomized trials and prospective studies comparing covered and bare self-expandable metal stents for the treatment of malignant obstruction in the digestive tract. Int J Med Sci 2013;10:825-835.

65. Tringali A, Hassan C, Rota M, Rossi M, Mutignani M, Aabakken L. Covered vs. uncovered self-expandable metal stents for malignant distal biliary strictures: a systematic review and meta-analysis. Endoscopy 2018;50:631-641.

66. Shamah SP, Chapman CG, Haider H, Liao C, Waxman I, Siddiqui UD. Partially covered versus uncovered self-expandable metal stents: coating nor diameter affect clinical outcomes. Dig Dis Sci 2019;64:2631-2637.

67. Mutignani M, Tringali A, Shah SG, et al. Combined endoscopic stent insertion in malignant biliary and duodenal obstruction. Endoscopy 2007;39:440-447.
68. Moon JH, Choi HJ, Ko BM, et al. Combined endoscopic stent-instent placement for malignant biliary and duodenal obstruction by using a new duodenal metal stent (with videos). Gastrointest Endosc 2009;70:772-777.

69. Mangiavillano B, Khashab MA, Tarantino I, et al. Success and safety of endoscopic treatments for concomitant biliary and duodenal malignant stenosis: A review of the literature. World J Gastrointest Surg 2019;11:53-61.

70. Lee JJ, Hyun JJ, Choe JW, et al. Endoscopic biliary stent insertion through specialized duodenal stent for combined malignant biliary and duodenal obstruction facilitated by stent or PTBD guidance. Scand J Gastroenterol 2017;52:1258-1262.

71. Vienne A, Hobeika E, Gouya H, et al. Prediction of drainage effectiveness during endoscopic stenting of malignant hilar strictures: the role of liver volume assessment. Gastrointest Endosc 2010;72:728-735.

72. Wagner HJ, Knyrim K, Vakil N, Klose KJ. Plastic endoprostheses versus metal stents in the palliative treatment of malignant hilar biliary obstruction. A prospective and randomized trial. Endoscopy 1993;25:213-218.

73. Sangchan A, Kongkasame W, Pugkhem A, Jenwitheesuk K, Mairiang P. Efficacy of metal and plastic stents in unresectable complex hilar cholangiocarcinoma: a randomized controlled trial. Gastrointest Endosc 2012;76:93-99.

74. Mukai T, Yasuda I, Nakashima M, et al. Metallic stents are more efficacious than plastic stents in unresectable malignant hilar biliary strictures: a randomized controlled trial. J Hepatobiliary Pancreat Sci 2013;20:214-222.

75. De Palma GD, Galloro G, Siciliano S, Iovino P, Catanzano C. Unilateral versus bilateral endoscopic hepatic duct drainage in patients with malignant hilar biliary obstruction: results of a prospective, randomized, and controlled study. Gastrointest Endosc 2001; 53:547-553.

76. Lee TH, Kim TH, Moon JH, et al. Bilateral versus unilateral placement of metal stents for inoperable high-grade malignant hilar biliary strictures: a multicenter, prospective, randomized study (with video). Gastrointest Endosc 2017;86:817-827.

77. Xia MX, Cai XB, Pan YL, et al. Optimal stent placement strategy for malignant hilar biliary obstruction: a large multicenter parallel study. Gastrointest Endosc 2019;91:1117-1128.

78. Boškoski I, Tringali A, Familiari P, et al. A 17 years retrospective study on multiple metal stents for complex malignant hilar biliary strictures: Survival, stents patency and outcomes of re-interventions for occluded metal stents. Dig Liver Dis 2019;51:1287-1293.

79. Hong W, Chen S, Zhu Q, Chen H, Pan J, Huang Q. Bilateral stenting methods for hilar biliary obstructions. Clinics (Sao Paulo) 2014;69:647-652.

80. Heo JY, Lee HS, Son JH, Lee SH, Bang S. Clinical outcomes of bilateral stent-in-stent placement using self-expandable metallic stent for high-grade malignant hilar biliary obstruction. Yonsei Med J 2018;59:827-833.

81. Lee TH, Moon JH, Choi JH, et al. Prospective comparison of endoscopic bilateral stent-in-stent versus stent-by-stent deployment for inoperable advanced malignant hilar biliary stricture. Gastrointest Endosc 2019;90:222-230.

82. Jang SI, Lee SJ, Jeong S, et al. Efficacy of a multiplex paclitaxel emission stent using a pluronic((R)) mixture membrane versus a covered metal stent in malignant biliary obstruction: a prospective randomized comparative study. Gut Liver 2017;11:567-573.

83. Zhu HD, Guo JH, Zhu GY, et al. A novel biliary stent loaded with (125)I seeds in patients with malignant biliary obstruction: preliminary results versus a conventional biliary stent. $J$ Hepatol 2012;56:1104-1111.

84. Hasimu A, Gu JP, Ji WZ, Zhang HX, Zhu DW, Ren W ×. Comparative study of percutaneous transhepatic biliary stent placement with 
or without Iodine-125 seeds for treating patients with malignant biliary obstruction. J Vasc Interv Radiol 2017;28:583-593.

85. Park DH, Lee SS, Lee TH, et al. Anchoring flap versus flared end, fully covered self-expandable metal stents to prevent migration in patients with benign biliary strictures: a multicenter, prospective, comparative pilot study (with videos). Gastrointest Endosc 2011;73:64-70.

86. Misra SP, Dwivedi M. Reflux of duodenal contents and cholangitis in patients undergoing self-expanding metal stent placement. Gastrointest Endosc 2009;70:317-321.

87. Hu B, Wang TT, Wu J, Shi ZM, Gao DJ, Pan YM. Antireflux stents to reduce the risk of cholangitis in patients with malignant biliary strictures: a randomized trial. Endoscopy 2014;46:120-126.

88. Lee YN, Moon JH, Choi HJ, et al. Effectiveness of a newly designed antireflux valve metal stent to reduce duodenobiliary reflux in patients with unresectable distal malignant biliary obstruction: a randomized, controlled pilot study (with videos). Gastrointest Endosc 2016;83:404-412.

89. Hamada T, Isayama $\mathrm{H}$, Nakai $\mathrm{Y}$, et al. Antireflux metal stent as a first-line metal stent for distal malignant biliary obstruction: a pilot study. Gut Liver 2017;11:142-148.

90. Sofi AA, Khan MA, Das A, et al. Radiofrequency ablation combined with biliary stent placement versus stent placement alone for malignant biliary strictures: a systematic review and meta-analysis. Gastrointest Endosc 2018;87:944-951.

91. Inoue T, Ibusuki M, Kitano R, et al. Endobiliary radiofrequency ablation combined with bilateral metal stent placement for malignant hilar biliary obstruction. Endoscopy 2020 Mar 24 [Epub ahead of print].

92. Hu BGD, Gao D, Zhang X, Zhang Y. Endobiliary radiofrequency ablation improve overall survival of cholangiocarcinoma: a multi-center randomized control study. Gastrointest Endosc 2016;83:AB126.

93. Yang J, Wang J, Zhou H, et al. Efficacy and safety of endoscopic radiofrequency ablation for unresectable extrahepatic cholangiocarcinoma: a randomized trial. Endoscopy 2018;50:751-760.

94. Berr F, Wiedmann M, Tannapfel A, et al. Photodynamic therapy for advanced bile duct cancer: evidence for improved palliation and extended survival. Hepatology 2000;31:291-298.

95. Ortner ME, Caca K, Berr F, et al. Successful photodynamic therapy for nonresectable cholangiocarcinoma: a randomized prospective study. Gastroenterology 2003;125:1355-1363.

96. Kahaleh M, Mishra R, Shami VM, et al. Unresectable cholangiocarcinoma: comparison of survival in biliary stenting alone versus stenting with photodynamic therapy. Clin Gastroenterol Hepatol 2008;6:290-297.

97. Wiersema MJ, Sandusky D, Carr R, Wiersema LM, Erdel WC, Frederick PK. Endosonography-guided cholangiopancreatography. Gastrointest Endosc 1996;43:102-106.

98. Giovannini M, Moutardier V, Pesenti C, Bories E, Lelong B, Delpero JR. Endoscopic ultrasound-guided bilioduodenal anastomosis: a new technique for biliary drainage. Endoscopy 2001;33:898-900.

99. Sharaiha RZ, Khan MA, Kamal F, et al. Efficacy and safety of EUSguided biliary drainage in comparison with percutaneous biliary drainage when ERCP fails: a systematic review and meta-analysis.
Gastrointest Endosc 2017;85:904-914.

100. Khashab MA, Valeshabad AK, Afghani E, et al. A comparative evaluation of EUS-guided biliary drainage and percutaneous drainage in patients with distal malignant biliary obstruction and failed ERCP. Dig Dis Sci 2015;60:557-565.

101. Itonaga M, Kitano M, Hatamaru K, et al. Endoscopic ultrasoundguided choledochoduodenostomy using a thin stent delivery system in patients with unresectable malignant distal biliary obstruction: A prospective multicenter study. Dig Endosc 2019;31:291-298.

102. Teoh AYB, Dhir V, Kida M, et al. Consensus guidelines on the optimal management in interventional EUS procedures: results from the Asian EUS group RAND/UCLA expert panel. Gut 2018;67:1209-1228.

103. Guo J, Giovannini M, Sahai AV, et al. A multi-institution consensus on how to perform EUS-guided biliary drainage for malignant biliary obstruction. Endosc Ultrasound 2018;7:356-365.

104. Paik WH, Lee TH, Park DH, et al. EUS-guided biliary drainage versus ERCP for the primary palliation of malignant biliary obstruction: a multicenter randomized clinical trial. Am J Gastroenterol 2018;113:987-997.

105. Bang JY, Navaneethan U, Hasan M, Hawes R, Varadarajulu S. Stent placement by EUS or ERCP for primary biliary decompression in pancreatic cancer: a randomized trial (with videos). Gastrointest Endosc 2018;88:9-17.

106. Park JK, Woo YS, Noh DH, et al. Efficacy of EUS-guided and ERCP-guided biliary drainage for malignant biliary obstruction: prospective randomized controlled study. Gastrointest Endosc 2018;88:277-282.

107. Bishay K, Boyne D, Yaghoobi M, et al. Endoscopic ultrasoundguided transmural approach versus ERCP-guided transpapillary approach for primary decompression of malignant biliary obstruction: a meta-analysis. Endoscopy 2019;51:950-960.

108. Chen YI, Callichurn K, Chatterjee A, et al; ELEMENT trial and for the Canadian Endoscopic Research Collaborative (CERC). ELEMENT TRIAL: study protocol for a randomized controlled trial on endoscopic ultrasound-guided biliary drainage of first intent with a lumen-apposing metal stent vs. endoscopic retrograde cholangio-pancreatography in the management of malignant distal biliary obstruction. Trials 2019;20:696.

109. Kunda R, Pérez-Miranda M, Will U, et al. EUS-guided choledochoduodenostomy for malignant distal biliary obstruction using a lumen-apposing fully covered metal stent after failed ERCP. Surg Endosc 2016;30:5002-5008.

110. Cho DH, Lee SS, Oh D, et al. Long-term outcomes of a newly developed hybrid metal stent for EUS-guided biliary drainage (with videos). Gastrointest Endosc 2017;85:1067-1075.

111. Mukai S, Itoi T, Tsuchiya T, Tanaka R, Tonozuka R. EUS-guided right hepatic bile duct drainage in complicated hilar stricture. Gastrointest Endosc 2017;85:256-257.

112. Ogura T, Yamamoto K, Sano T, et al. Stent length is impact factor associated with stent patency in endoscopic ultrasound-guided hepaticogastrostomy. J Gastroenterol Hepatol 2015;30:1748-1752. 


\section{Supplementary material}

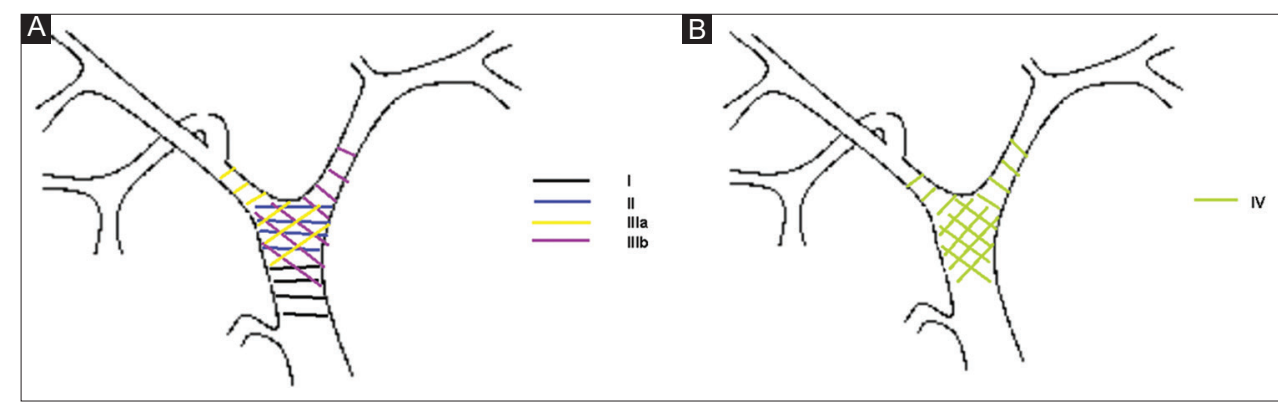

Supplementary Figure 1 Bismuth-Corlette classification for hilar malignant lesions. (A) In type I (black) the stricture is in the common hepatic duct, in type II (blue) the stricture interrupts the hepatic bifurcation, in type III the stricture reaches the right (IIIa, yellow), or the left hepatic duct (IIIb, purple). (B) Type IV (green) strictures involve the hepatic confluence and both of the hepatic ducts 